\title{
Perception of gender stereotypes, machismo and marianismo in Ecuadorian adolescents: A focus group study
}

\author{
Verónica Pinos ${ }^{\text {(D) } 1, ~ G u i d o ~ P i n o s ~}{ }^{2,3}$, Rachid Baitar ${ }^{5,6}$, Monserrath Jerves ${ }^{4,5}$, Paul Enzlin $^{6}$ iD \\ ${ }^{1}$ Dirección de Investigación de la Universidad de Cuenca (DIUC), Ecuador. \\ ${ }^{2}$ Facultad de Ciencias Médicas, Universidad de Cuenca, Ecuador. \\ ${ }^{3}$ Centro de Reposo y Adicciones (CRA), Cuenca, Ecuador. \\ ${ }^{4}$ Facultad de Filosofía, Letras y Ciencias de la Educación, Universidad de Cuenca, Ecuador. \\ ${ }^{5}$ Cifsex, Universidad de Cuenca, Ecuador. \\ ${ }^{6}$ Institute for Family and Sexuality Studies, KU Leuven, Belgium.
}

Autor para correspondencia: veronica.pinos@ucuenca.edu.ec

Fecha de recepción: 11 de abril 2016 - Fecha de aceptación: 3 de octubre 2016

\begin{abstract}
Recent studies increasingly demonstrated that gender differences are linked with macro-cultural factors. The stereotypes in Latin America that shape gender roles are machismo and marianismo. In contrast, with the ample publications on the importance of machismo, empirical research on machismo and certainly marianismo is still in its infancy despite both being well known concepts. To this end, the present study explores how Ecuadorian adolescents from Cuenca experience, and make sense of, gender stereotypes. Twelve focus groups were carried out, involving 127 male and female adolescents. The data were analyzed using thematic analysis. Four categories related to machismo emerged: cognition regarding machismo, manifestations of machismo, adolescents' expectations by gender, and advantages of traditional norms. The results showed that participants know about machismo and stated that gender stereotypes are transmitted to adolescents by parents and society in general to the next generations. Our participants blame gender stereotypes for the inequality in the society, but at the same time, their intervention showed that they absorbed these stereotypes in their belief system.
\end{abstract}

Keywords: Machismo, marianismo, gender stereotype, double standard, adolescents.

\section{RESUMEN}

Diferentes estudios han demostrado que las diferencias de género están vinculadas con los factores macro-culturales. Los estereotipos que dan forma a los roles de género en América Latina son el machismo y el marianismo. A pesar de que ambos conceptos son extensamente conocidos, en contraste con la gran cantidad de publicaciones teóricas sobre la importancia del machismo, las investigaciones prácticas sobre el machismo y el marianismo están en su infancia. El presente estudio explora cómo los adolescentes cuencanos experimentan y dan sentido a los estereotipos de género. Para ello, se llevaron a cabo doce grupos focales, con la participación de 127 adolescentes de ambos sexos. Los datos fueron analizados a través de un Análisis Temático. Dentro del análisis surgieron cuatro categorías relacionadas con el machismo: la cognición en relación con el machismo, las manifestaciones de machismo, las expectativas de género de los adolescentes por sexo y las ventajas de las normas tradicionales. Los resultados demostraron que los participantes conocen sobre el machismo e indicaron que los estereotipos de género son transmitidos a las nuevas generaciones a través de los padres y la sociedad en general. Los participantes responsabilizaron a estos estereotipos por la desigualdad entre géneros en nuestra sociedad; pese a esto, a través de sus intervenciones se evidenció que han absorbido e internalizado estos estereotipos en su sistema de creencias. En consecuencia, es necesario trabajar con ellos a través de programas que tengan como objetivo el alcanzar la igualdad de género.

Palabras clave: El machismo, el marianismo, estereotipo de género, doble estándar, adolescentes. 


\section{INTRODUCTION}

Most gender differences regarding attitudes and behaviors are culturally determined (Conrad, 2011). Indeed, in the socialization process, behavioral guidelines are directly and indirectly offered to new generations consistent to the rules and the expectations of society. These guidelines are assimilated by adolescents and reinforced by the same entities that transmit them (Shibley \& DeLamater, 2006; Crooks $\&$ Baur, 2009). For instance, adolescents learn cultural gender stereotypes from their families, school, peers, media and society in general (González, 1999; Crooks \& Baur, 2009). In Latin American society, machismo and marianismo are the predominant cultural stereotypes that shape gender roles (Shibley \& DeLamater, 2006; Crooks \& Baur, 2009; Sequeira, 2009). The stereotype of machismo is well known and often referred to in cultural studies on Latin America (Mayo, 1997; Mirandé, 1997; Hardim, 2002; Duque \& Montoya, 2006; Sequeira, 2009). This stereotype emphasizes the idea of hyper masculinity in men (Hardim, 2002; Duque \& Montoya, 2006). The word macho means male animal in Spanish; in fact, machismo emphasizes the idea of an almost animal masculinity. That is, the main characteristics of machismo are aggressiveness and hypersexuality (Ingoldsby, 1985/1991). Aggressiveness is demonstrated through authoritarianism, aggression, and dominance toward women and men (Mayo, 1997; Mirandé, 1997; Hardim, 2002; Duque \& Montoya, 2006; Sequeira, 2009). Hypersexuality refers to the continuous conquest of women and the pursuit of several sexual partners (Hardim, 2002; Noland, 2006; Sequeira, 2009).

In women, the parallel behavior is named hembrismo, stemming from the word hembra meaning female animal (Mirandé, 1997). However, hembrismo is not the ideal of femininity; rather, the expectations for behavior of women are described by religion in what is known as marianismo; this term is derived from the Virgin Mary (Sequeira, 2009). This traditional Latin American female stereotype considers women as semi divine, spiritually and morally superior to men (Ingoldsby, 1985 \& 1991). More specifically, marianismo provides the main guidelines for women's behavior. That is, to maintain their value to men, women are expected to: be reliant, and submissive, sacrifice themselves for motherhood, endure violence and adultery from their husband and preserve their virginity until marriage (Wolf, 1980; Ingoldsby, 1985 \& 1991; Sequeira, 2009).

The relevance of gender stereotypes is due to their impact on sexuality. Taken together, machismo and marianismo both contribute to the double standard in Latin society where men are encouraged to be sexually aggressive and active while women are devalued if they present the same behavior (Sequeira, 2009). Another impact is that gender stereotypes or beliefs, and expectations and opinions about gender all influenced the perception we have about others and about ourselves within a couple (Crooks \& Baur, 2009). That is, studies have confirmed the influence of adolescent socialization processes on sex behaviors and beliefs (Berglund et al., 1997; Kinsman et al., 2000; Thianthai, 2004; Tangmunkongvorakul \& Kane, 2005; Garduño et al., 2015; Hiller \& Baudin, 2016). For instance, inside the Latin American family, male and female roles are learned through socialization (Mayo, 1997; Salyers, 1998; Baldwin \& DeSouza, 2001; Raffaelli \& Ontai, 2001/2004; Barker et al., 2010; Lamas, 2016). In this regard, some conceptual theorical articles have shown that cultural expectations encouraged Latin women to sacrifice their own needs. Precisely, Latin women gave priority to the physical desires of their men, boosted their egos, and endured their violence (Lugo, 1985; Quiñonez \& Resnick, 1996; Olavarría, 2001; Briones-Vozmediano et al., 2016). Moreover, women have more conservative values regarding sexual conduct than men (Succoff, 2001). Empirical studies revealed that in Latin America men and women are silenced by their prescribed gender roles, which in turn limit their ability to fully engage in safe sex practices (Salyers, 1998; Viveros, 2002; Villarruel \& Rodriguez, 2003; Noland, 2006; Cianelli et al., 2008; Stoyanova \& Hope, 2012; Champion \& Szlachta, 2016).

In contrast, with the ample theoretical publications on the role of machismo and marianismo, empirical research on gender stereotypes is still in its infancy. Qualitative research on these gender stereotypes is nonexistent in Ecuadorian adolescents. Hence, this study aims to show how Ecuadorian adolescents from Cuenca experience and make sense of machismo. 


\section{METHODS AND MATERIALS}

\subsection{Procedure and participants}

The data were collected during the academic year of 2009-2010. The research was based on focus groups with adolescents of one public and one private high school from Cuenca, Ecuador. The high schools were selected as typical cases from the high schools participating in a broader research project on sexuality and sexual education in adolescents. The sample was purposefully selected in agreement with the high schools' advisers. Three groups of study of similar size were recruited in each high school: one group of the first year of high school (early adolescents), one group of fourth year (middle adolescents) and one group of the sixth or last year of high school (late adolescents). Only students between 11 and 19 years old participated in this study. The sample was constituted of 127 adolescents. Participants were divided into 12 groups by gender, grade level, and high school type. $44.19 \%$ were male, and $55.90 \%$ were female; $36.22 \%$ were in the first year of high school, $32.28 \%$ were in the middle of high school, and $31.50 \%$ were in the last year of high school. In terms of school-type, $51.18 \%$ studied in public high school, and $48.82 \%$ studied in private high school.

We selected a qualitative research strategy to obtain in-depth information about phenomena in a specific context (Hernandez et al., 2007). In total, twelve focus groups sessions were held. The moderators were one male and four female professionals with backgrounds in psychology, psychiatry, and education. These researchers had several preparatory sessions in which the research protocol and the focus group discussion guide were reviewed and approved. The guide was validated by pilot testing. It had two parts: the first part had stories about violence within couples, and the second part had discussion questions. All focus groups were conducted in Spanish.

Procedures were approved by each collaborating high school. Adolescents were informed about the objectives and procedures of the research. Each participant signed an informed consent form in which confidentiality and anonymous analysis of data were assured. Each participant had to use madeup names during the focus group. After participating in the focus group discussions, adolescents attended a conference about violence and its prevention. Here, participants could discuss their main concerns and ask expert questions about violence prevention.

\subsection{Data coding and analysis}

Discussions were recorded, transcribed verbatim and analyzed. Thematic analysis with a semantic or explicit level was used for identifying, analyzing and reporting themes within data (Braun \& Clarke, 2006). Initial codes were generated through a repeated process of reading all transcripts, identifying codes, and assembling the former into themes. Different strategies were used to check the accuracy of the findings: the transcriptions were checked to prevent mistakes, and three researchers analyzed and coded the data. Final codes and themes were only used when consensus was reached.

\section{RESULTS}

Thematic analysis generated four main categories related to machismo: (1) cognition regarding machismo, (2) manifestations of machismo, (3) adolescents' expectations by gender, and (4) advantages of old fashion behaviors (see Table 1 for an overview of all themes and sub-themes).

\subsection{Cognitions regarding machismo}

In all focus groups, machismo was linked to how adolescents experienced their sexuality. Some themes concerning machismo were distinguished such as concept, characteristics, transmission, and machismo in Cuenca. 
Table 1. Themes and sub-themes found in the analysis.

\begin{tabular}{|c|c|}
\hline Themes & Subthemes \\
\hline Cognition regarding machismo & $\begin{array}{l}\text { Concept } \\
\text { Characteristics } \\
\text { Transmission } \\
\text { Machismo in Cuenca }\end{array}$ \\
\hline Manifestations of machismo & $\begin{array}{l}\text { Double standard } \\
\text { Overgeneralization } \\
\text { Pressure regarding gender expectations }\end{array}$ \\
\hline Adolescents' expectations by gender & $\begin{array}{l}\text { Female adolescents and premarital sex } \\
\text { Male adolescents and premarital sex }\end{array}$ \\
\hline Advantages of traditional norms & $\begin{array}{l}\text { Awareness } \\
\text { Female self-respect } \\
\text { Less pregnancies, STD and abortion }\end{array}$ \\
\hline
\end{tabular}

\section{Concept}

Machismo was described by several participants as discrimination and control of men over women:

$\sqrt{ }$ Machismo is a form of discrimination against women (Puzo, male, age 14).

$\checkmark$ It's like the man feels or thinks that he is superior to women, or he thinks that he can do whatever he wants to her, or that she will do whatever he wants (Alejita, female, age 15).

However, some participants conceptualized machismo as jealousy or acts of physical violence only:

$\sqrt{ }$ Machismo is Jealousy: both men and women are jealous, so both are machistas. For example, because there are times when men have things to do, and women do not allow them to go out, so they start to argue (Lulú, female, age 15).

$\sqrt{ }$ Machismo is when they beat each other, men to women or women to men. This is machismo because they are hitting (Titi, female, age 11).

Participants mentioned feminismo as a related concept; nevertheless, most of them considered it as a feminine version of machismo, the hembrismo:

$\sqrt{ }$ Feminismo is like machismo but in women (Jey-Jey, male, age 15).

$\sqrt{ }$ Feminismo is to think that all of us are equal (laughs), women have the same rights, and must be treated like a man (José, male, age 17). [Interruption: No, it is that women believe they are superior to men (Wario, male, age 17)].

\section{Characteristics of machismo}

Some features of machismo were reported by adolescents such as exercise of power, aggression toward men and women, arrogance, coldness, hypersexuality, and leadership.

As stated by the participants, the macho man shows his power by controlling women:

$\checkmark$ Some men control the way that women should dress. These women must dress completely covered (Gaby, female, 16).

$\sqrt{ }$ Some men do not like it when women work. They want women to stay at home and take care of kids and do other household tasks (Nyky, female, age 15).

Another important feature of machismo remarked on by participants is the aggression toward women and men:

$\checkmark$ The macho thinks that he is amazing; he can do anything. He will beat both women and men (José Eduardo, male, age 17).

Arrogance or feelings of superiority is another characteristic of machismo reported by participants:

$\sqrt{ }$ The macho believes that he is more important than others (Blanca, female, age 17).

The participants also pointed out that the macho demonstrates his superiority by dominating his feelings. He does not allow "soft" feelings, only aggression and domination: 
$\sqrt{ }$ The macho never cries because he never feels anything because he is the boss (José Eduardo, male, age 17).

As said by the participants, machismo also is set apart by hypersexuality. They associate machismo with promiscuity and a preoccupation with sex to confirm masculinity:

$\sqrt{ }$ They think that when a man has sex frequently with different women, he is more masculine (Pamela, female, age 16).

The participants also compared the macho man to a macho alpha in animals. Hence, like in animals, he is the alpha leader. All males want to stay with him, and all women want to engage in intercourse with him:

$\sqrt{ }$ The macho alpha dominant is the head. All animals, all females in the herd want to stay with him because he is the most powerful male. In society, the alpha male would become the macho man, the daddy of all women [el papi de las nenas]. So, all women want to have sex with him (Wario, male, age 17).

\section{$\underline{\text { Transmission }}$}

With respect to machismo in Ecuador, the participants reported that this stereotype is transferred by family and society:

$\checkmark$ This concept was introduced by family and society. How a man must be macho is an old concept (Wario, male, age 17).

$\sqrt{ }$ There has been machismo since the Stone Age. Machismo is going to last because children grow up with that mentality; machismo is taught from parents to children (Carlos, male, age 17).

They stated that women, especially mothers, are responsible for teaching machismo and feminismo; thus, the change should start in the family:

$\sqrt{ }$ I believe that machismo is something created not only for men but also for women because women make men their priority. That is, women prioritize men (Africano, male, age 15).

$\checkmark$ Since they are children, their mothers put this concept into their head and mothers leave them with that thought. Then they are a little bit machistas or a feministas instead of thinking of equality (Wario, male, age 17).

\section{Machismo in Cuenca}

Participants stated that machismo has always existed in Cuenca. They also thought that it will remain. Yet, they considered that it is gradually decreasing:

$\sqrt{ }$ I think there is still machismo...I think that machismo will exist for a long time. (Leonel, male, age 17).

$\sqrt{ }$ Here there is machismo principally, although it is decreasing (Jey-Jey, male, age 15).

According several participants are machismo and feminismo causes of inequality between men and women, so they should be eradicated:

$\checkmark$ I believe that there should not be machismo or feminismo because both men and women have the same rights and the same competencies (Jey-Jey, male, age 15).

\subsection{Manifestations of machismo}

The adolescents pointed out some aspects that affect their lives such as double standards, overgeneralized, and pressure regarding gender expectations.

\section{Double standard}

Another aspect of gender stereotypes perceived by adolescents is the double standard in their society. Participants documented differences in appreciation in the use of violence, whereas men can use violence, women are rejected when expressing the same behavior:

$\sqrt{ }$ When a woman is hitting on a person, she is a bitch. Yet, when a man is doing the same, he is the best (Wario, male, age 17). 
Participants also perceived the double standard between man and woman regarding sexual freedom and effectiveness. That is, machismo and feminismo allow men to be promiscuous and women to be chaste but it is not possible to go the other way around; moreover, the woman can be affectionate but men cannot:

$\sqrt{ }$ When you see two women holding hands nothing happens. Yet, when you see two men doing the same, they are considered gay. When a woman is seen kissing eight men, she is an easy woman. Yet, when a man is seen doing the same, he is cool. You can see the difference between machismo and feminismo (Juan Diego, male, age 14).

Female participants explained that this inequality is based on biological factors. In pregnancy for instance woman will ultimately have to assume the main responsibility for the child:

$\sqrt{ }$ There is machismo, particularly in the sexual aspect, because a man has nothing to lose; women are those who lose because they get pregnant (Mónica, female, age 17).

They remarked that men can leave women alone with the responsibility to take care of their child:

$\sqrt{ }$ Sometimes, men go away and let women alone with the pregnancy (Daysi, female, age 17).

$\sqrt{ }$ If she gets pregnant, she will leave her studies to take care of her child (Anita, female, age 15).

\section{Overgeneralization}

Male participants expressed that due to machismo and feminismo the conception of men is generalized:

$\sqrt{ }$ I mean...there are the typical phrases that state: "all men are the same"; "all men are players"; "all men cheat". I mean, people say that "all men are the worst", but do not say that about women, only few women are like this. Then, I think that those kinds of comments are also feministas (José Eduardo, male, age 17).

\section{Pressure regarding gender expectations}

Participants expressed that they feel a strong pressure to behave in line with the expectations of gender; participants stated that due to machismo, men are pushed to have intercourse even when they do not feel ready:

$\checkmark$ Perhaps the man is not ready or perhaps he just wants to try it. [Interruption: men are like little monkeys, very curious (Belén, female, age 17)], or by the influence of friends, so typical "you are the fool, the coco [a virgin man] " or "it is like you have to prove that you are a man" (Angélica, female, age 16).

Participants reported that women have the same sexual desires as men; the only difference is that men can express them directly:

$\sqrt{ }$ Men are more obvious about what we want. Women do not show their desires, but it is not true that men do not think about love (Patucho, male, age 16).

Participants further asserted that religious beliefs preserved through generation, produce especially in female adolescents, fear and rejection of sex:

$\checkmark$ Cuenca is a closed society principally due to the old religious beliefs from Catholicism. So, we must follow what the priest says. That is, what according him is good and what is bad. That creates taboos. Then, parents tell us that we cannot do something because this must cause damage. For example, it is wrong to dance so close (Wario, male, age 17).

$\sqrt{ }$ For example, when I talk about sex with a female friend of mine, she takes it as something disgusting. It is wrong, because she is closing her mind; for me, sex is not bad; but there are many people like my friend who fear and dislike sex. That is because they are narrow minded (José Eduardo, male, age 17).

\subsection{Adolescent's expectations by gender}

The participants showed ideas regarding their expectations per gender. That is, what behavior is expected for a female or male adolescent concerning premarital intercourse. 


\section{Female adolescents and premarital sex}

The participants considered that intercourse for women is a sacred value; that is, a crucial experience for their future:

$\sqrt{ }$ Intercourse is not like a kiss, no. In my opinion, this is very sacred; I think, in a woman's life, it is essential (Angélica, female, age 16).

As stated by the participants, women had the responsibility to remain virgins, so women must control their sexual desires:

$\sqrt{ }$ Men seek to satisfy their sexual needs; they view women like as a sexual toy. However, when it happens with a woman, it is because she allowed it to happen (Alejita, female, age 15).

$\sqrt{ }$ Women have sexual desires, so we must control them ( $\mathrm{Lu}$, female, age 14).

Female participants consider it necessary to analyze the consequences of their acts. That is, a bad decision about sex is believed to have negative consequences such as pregnancy and sole parenting:

$\checkmark$ A woman should be aware of the consequences. If the girl gets pregnant, her partner will perhaps leave her; then, the girl is who faces the worst part. Also, she must consider that he may not love her, and he only wants to have sex with her (Diana2, female, age 12).

Another consequence for women, following the participants, is the loss of their purity. Therefore, it was suggested that they could no longer offer it to men. Indeed, for women, intercourse before marriage was considered a failure:

$\sqrt{ }$ When she later would have another boyfriend, she would feel bad about herself. She would think that the former boyfriend failed her; she would no longer be able to give herself to another guy because she is not pure anymore, and, then, she would feel bad about it (Daysi, female, age 17).

Moreover, participants stated that if a woman agrees to have intercourse before marriage, the man would change his mind toward her:

$\checkmark$ The man would realize that she does not have respect for herself, and [interruption-If they have sex, it is not because of love or anything] he would change with her [interruption-she would be an easy woman] (Jessica, female, age 17).

The participants indicated that it is very important for women to remain a virgin before the marriage, because men look for a virgin woman as a wife:

$\checkmark$ In the end, men are not looking for a woman who is an easy woman. They are looking for one who is secure about herself and does not have sex before marriage (Katy, female, age 15).

Moreover, they also stated that virgin women will be able to change men:

$\checkmark$ I mean, there are men who are such pigs [pervert], (laugh). They are just looking for sex...but there are men who really expect a woman to change them...there are women who have changed men (Karla, female, age 14).

\section{Male adolescents and premarital sex}

The participants consider that men always look for sex to demonstrate their masculinity:

$\checkmark$ Almost all men look for sexual relationships, because of the desire to be a man (Anthony, male, age 19).

$\sqrt{ }$ Men are looking for a score, which pertains to the number of intercourses with different women (Sevelindo, male, age 17).

Also, the participants noted that there are two types of woman for men, with different expectations for each. That is, one kind of woman is for experimentation, and another for a serious relationship:

$\sqrt{ }$ It depends on how you have sex, because if you are going to have sex with someone who you love, it is an act of love with this person. However, when you want to have sex with someone because you want to explore what it is like, or because your friends have told you it is good, then, you are having sex because you want to have new experiences. This is not love; this is only because of necessity (Java, male, age 17).

The participants believe that there are several solutions when only the man, and not his partner, wants to have sex. The presence of respect, control and patience are mentioned as chief personal qualities that can help to resolve such disagreements: 
$\sqrt{ }$ If there is love and respect, the couple should talk (Jessica, female, age 17).

$\checkmark$ He must control his desires (Leonel, male, age 17).

$\sqrt{ }$ A man should wait for her until she is ready for sexual intercourse (Carlos, male, age 17).

Other alternatives were also proposed by participants as:

$\checkmark$ Jerk off (Sevelindo, male, age 17).

$\sqrt{ }$ Go to a prostitute (laughs) (Patucho, male, age 16).

$\checkmark$ He should find a doll like this, an inflatable doll, which is a sexual toy (laughs) (Mark, male, age 17).

\subsection{Advantages of traditional norms}

The participants considered some positive aspects in traditional gendered norms, such as awareness, female self-respect, fewer pregnancies, STD s and abortion.

\section{Awareness}

Some participants believed that some traditional norms had merit. For example, it was suggested that these norms helped to preserve certain values:

$\sqrt{ }$ In the past, women were more conservative and conscious (Verónica, female, age 16).

$\checkmark$ Nowadays, neither male nor female are saints. All women and men are devils (Anthony, male, age 19).

\section{Female self-respect}

Participants suggested that the old-fashioned norms increased awareness about the importance of upholding self-respect through maintaining their chastity:

$\sqrt{ }$ More than anything, right now, women do not make men respect them. They are easy with men (Verónica, female, age 16).

$\sqrt{ }$ The world has changed; most women are easy. They do not ask men to respect them (Lu, female, age 14).

According to the participants, freedom is a present-day expression of women's desires. Participants consider this not desirable:

$\checkmark$ Nowadays, women are easy; they are looking for a man. Women are dating with several men. For instance, when women are at a party, they kiss with one man, and then with another man. For a woman, that is unattractive (Gaby, female, age 16).

\section{Fewer pregnancies, STD and abortions}

Participants claimed that due to current weak norms there are consequences like early pregnancies, STD and abortion:

$\sqrt{ }$ Nowadays, there is no strong parental control. There is more freedom; due to this, pregnancy and abortion occurs more often than before (Anthony, male, age 19).

$\checkmark$ F. Women are protected of sexual disease and pregnancy by not having sex (Mariela, female, age 17).

\section{DISCUSSION}

In general view, the adolescents showed more knowledge regarding machismo than marianismo. In fact, machismo was presented during most of their interventions. For example, the adolescents showed knowledge regarding machismo such as concept, characteristics, transmission, and the presence of machismo in Cuenca. Nevertheless, few confusions regarding machismo were found, such as to define machismo as jealousy and violence only. The amount of knowledge about machismo and its characteristics is not a surprise since it is a well-known concept in Latin-American society. Among the features of machismo, participants highlighted dominance, exercise of power, aggressiveness, hyper 
sexuality and leadership (Lugo, 1985; Ingoldsby, 1985/1991; Quiñonez \& Resnick, 1996; Mayo, 1997; Mirandé, 1997; Salyers, 1998; Olavarría, 2001; Hardim, 2002; Noland, 2006; Duque \& Montoya, 2006; Cianelli et al., 2008; Sequeira, 2009; Briones-Vozmediano et al. 2016). This is different from the female stereotypes that are less known concepts. For instance, the concept that adolescents gave to feminismo sometimes could fit with the concept of hembrismo or the feminine version of machismo (Mirandé, 1997), and others times with marianismo (Sequeira, 2009). On the other hand, the participants recognized that Cuenca-Ecuador society is machista as other Latin American cultures (Crooks \& Baur, 2009; Shibley \& DeLamater, 2006; Sequeira, 2009). They considered that gender stereotypes are transmitted by family and society (Berglund et al. 1997; Conrad, 2011; Crooks \& Baur, 2009; González, 1999; Kinsman et al., 2000; Thianthai, 2004; Tangmunkongvorakul \& Kane, 2005; Garduño et al., 2015; Hiller \& Baudin 2016). What is remarkable is that they stated that women, especially mothers, are predominantly responsible for transferring these gender stereotypes to children, as well as tolerating this behavior; hence, eradication of machismo should start at home.

Adolescent participants described some manifestations of machismo, such as double standard, over-generalization, and blamed machismo, as pressuring them to be a certain way. Following those participants, violence and sexual freedom are considered a privilege for men, but a mistake for women (Sequeira, 2009). The male adolescents expressed that more than feel free for this, they feel pressured by machismo and with respect to sexuality especially. Machismo has an ambiguous influence on sexuality; that is, there is a dialectical tension between sexual freedom and pressure making a finer distinction in what the dominant discourse in society is on machismo, namely, cold and insensitive men with all the benefits of sexual freedom appear to experience some negative effects themselves. In contrast, they felt that woman have a lot of restrictions regarding their sexuality, this causes fears and sex displeasure in them. Thus, men and women feel that they should fit with sexual expectations regarding their gender stereotypes. In any event, participants considered that women should have the same rights as men. Nevertheless, some of their arguments showed that their ideas regarding how to "live their sexuality" fit with stereotypes of gender that they criticized. They mainly justify the unequal treatment regarding sexual freedom because a woman will be the one assuming maternity.

Adolescent's expectations by gender: Marianismo was not mentioned by any of the participants. Still, this concept seemed to be implicitly present when they showed their expectation of women. Results showed that participants still believe that women should remain virgins until marriage to maintain women's value for man and bring men to a superior level of spirituality (Wolf, 1980; Ingoldsby, 1985/1991; Sequeira, 2009). This implies that while men go through stages regarding sexuality in their life, women do not have the same opportunity. That is, women are classified as the ones who are either useful for (A) obtaining sex experience (bad woman) or (B) for having a serious permanent relationship that can change men because they are considered morally superior to men who are dominated by animal instincts. This is concerning because this idea can perturb a normal sexual development because men and women should deal with machistas and marinistas stereotypes as guidelines to fit in society.

Advantages of traditional norms: Another finding pertained to participants' statements that some norms of machista influence from the past should be maintained in society. For example, female selfcontrol, and abstinence strengthens social values, which turns into helping to prevent early pregnancies, STD and abortions.

In general, masculinity and femininity have been quite easily interpreted as internalized sex roles, the product of social learning or socialization, that is, in the sex role theory, action is linked to a structure defined by biological difference and not to a structure defined by social relation (Connell 1995). In this regard, the impact of roles on society and the species and the utility of roles for society and species need to be considered (Sinnott \& Rabin 2012). This research shows the need to implement education programs to clarify not only concepts but also values. From this, feminist as a social movement, ideology, theory, philosophy, worldview and a way of life not only struggled to dismantle patriarchy and transform societies, but they also responded to the cultural contexts in which people live; it could be used as ideology and to disrupt the gendered discourses and has a substantial contribution to changing the female situation (Milojevic, 2008; Ioana, 2013; Ampofo et al., 2015; Fitch et al., 2016). 


\section{CONCLUSION}

The purpose of this study was to show how Ecuadorian adolescents from Cuenca experience and make sense of gender stereotypes. Four main categories emerged: Cognition regarding machismo, Manifestations of machismo, Adolescent's expectations by gender and Advantages of traditional norms. Participants perceive gender stereotypes as an imposition of social factors, and identified some of machismo's characteristics. As stated by the participants, the family is the most logical place to break the vicious circle that leads to machista behaviors. Participants consider that gender inequality in their expectations is wrong, but at the same time, participants showed that they have absorbed this system of beliefs. Hence, participants held traditional ideas towards gender that fit with machismo and marianismo; both support violence and the double standard in Latin society. These findings show the need to work with the adolescents and their families, not only to clarify concepts but also to encourage them to break gender roles and promote the equality between sexes. More research in this interesting field is necessary to understand the sexual dynamic in this specific culture.

Limitation and future directions: This qualitative study was conducted with the aim of collecting the words of adolescents, their knowledge and views about machismo. As so often with qualitative research, we should be careful in generalizing the findings from the small sample of adolescents provided from a specific context, Cuenca. This research should be a baseline to develop training programs, which should aim to eliminate these stereotypes of gender. Furthermore, it seems that there is the need to perform research with emphasis on marianismo, which is a theme less studied than machismo. Moreover, a longitudinal qualitative research to explore how these perceptions of adolescents change over time, and a research with adolescents, adults with emphasis on the influence of parents.

\section{ACKNOWLEDGE}

The authors are grateful to the VLIR-UOS program between the University of Cuenca and the council of Flemish Universities for funding this research, and like to express gratitude to Silvia Lopez and Sofie Maenhout for their assistance in the data gathering.

\section{BIBLIOGRAPHY}

Ampofo, A.A., E. Asa-Adjei, M. Kyerewaa-Brobbey, 2015. Feminisms and acculturation around the globe. In: International Encyclopedia of the Social \& Behavioral Sciences, pp. 905-911.

Baldwin, J., E. DeSouza, 2001. Modelo de María and Machismo: the social construction of gender in Brazil. Interamericam Journal of Psychology, 35(1), 9-29.

Barker, C.H., K.L. Cook, J. Borrego, 2010. Addressing cultural variables in parent training programs with Latino families. Cognitive and Behavioral Practice, 17(2), 157-166.

Berglund, S., J. Liljestrand, M. De María, N. Salgado, E. Zelaya, 1997. The background of adolescent pregnancies in Nicaragua: A qualitative approach. Social Science \& Medicine, 44(1), 1-12.

Briones-Vozmediano, E., C. Davó-Blanes, M. García-de la Hera, I. Goicolea, C. Vives-Cases, 2016. Discursos profesionales sobre la violencia del compañero íntimo: implicación en la atención de las mujeres inmigrantes en España. Gaceta Sanitaria, 30(5), 326-332.

Champion, J.D., A. Szlachta, 2016. Self-identified sexual orientation and sexual risk behavior among HIV-infected Latino males. Journal of the Association of Nurses in AIDS Care, 27(5), 585-594.

Cianelli, R., L. Ferrer, B. Mcelmurry, 2008. HIV prevention and low-income Chilean women: Machismo, marianismo and HIV misconceptions. Culture, Health \& Sexuality, 10(3), 297-306.

Connell, R., 1995. Masculinities. Berkeley, CA: University of California Press. 
Conrad, P., 2011. Antropología Cultural (12a ed.). México D.F., México: McGraw-Hill Publ. Comp.

Crooks, R., K. Baur, 2009. Nuestra Sexualidad (10ª ed.). México D.F, México: Cengage Learning.

Duque, L., N. Montoya, 2006. Características de las personas: Actitudes machistas. Antioquia: Previva, Universidad de Antioquia.

Fitch, K., M. James, J. Motion, 2016. Talking back: Reflecting on feminism, public relations and research. Public Relations Review, 42(2), 279-287.

Ioana, I.M., 2013. The evolution of the Romanian feminism in the 20th century. Procedia - Social and Behavioral Sciences, 81, 454-458.

Garduño, A.S., R. Díaz, N. Reyes, C. Hurtarte, F. López, M. Moreno, A. Romero, J. Hernández; M. Domínguez, 2015. Roles de género y diversidad: Validación de una escala en varios contextos culturales. Acta de Investigación Psicológica, 5(3), 2124-2147.

Giraldo, O., 1972. El Machismo como fenómeno Psicocultural. Revista latino-americana de psicología, 4(3), 295-309.

González, B., 1999. Los estereotipos como factor de socialización de género. Comunicar, 12, 79-88.

Hardim, M., 2002. Altering masculinities: The Spanish conquest and the evolution of the Latin American machismo. International Journal of Sexuality and Gender Studies, 7(1), 1-22.

Hiller, V., T. Baudin, 2016. Cultural transmission and the evolution of gender roles. Mathematical Social Sciences, 84, 8-23.

Ingoldsby, B., 1985. A theory for the development of machismo. The Annual Meeting of the National Council of Family Relation. Dallas, TX, 1-13 pp.

Ingoldsby, B., 1991. The Latin American family: Familism vs machismo. Journal of Comparative Family Studies, 22(1), 57-62.

Kinsman, J., S. Nyanzi, R. Pool, 2000. Socializing influences and the value of sex: the Experience of Adolescent school girls in rural Masaka, Uganda. Culture, Health \& sexuality, 2(2), 151-166.

Lamas, M., 2016. Mujeres guerrerenses: Feminismo y política. Revista Mexicana de Ciencias Políticas y Sociales, 61(226), 409-424.

Lugo, C., 1985. Machismo y violencia. Nueva Sociedad, 78, 40-47.

Mayo, Y., 1997. Machismo, fatherhood and the Latino family. Journal of Multicultural Social Work, 5(1/2), 49-61.

Milojevic, I., 2008. Timing feminism, feminising time. Futures, 40(4), 329-345.

Mirandé, A., 1997. Hombres y machos: Masculinity and Latino culture. Boulder, CO: Westview.

Noland, C., 2006. Listening to the sound of silence: Gender roles and comunication about sex in Puerto Rico. Sex Roles, 55(5), 283-294.

Olavarría, J., 2006. Hombres: Identidades y violencia. Flacso. Available at http://joseolavarria.cl/wpcontent/uploads/downloads/2010/10/2do-Encuentro-Hombres-Identidad-y-violencia.pdf, 175 pp.

Quiñonez, Y., R. Resnick, 1996. The Impact of Machismo on Hispanic Women. Sage publications, 11(3), 257-277.

Raffaelli, M., L. Ontai, 2004. Gender socialization in Latino/a families: Results from two retrospective studies. Sex Roles, 50(5/6), 287-299.

Raffaelli, M., L. Ontai, 2001. She's 16 years old and there's boys calling over to the house: An exploratory study of sexual socialización in Latino families. Culture, Health \& Sexuality, 3(3), 295-310.

Salyers, S., 1998 "Machismo/Marianismo attitudes, employment, education, and sexual behavior among women in Ecuador and the Dominican Republic. Journal of Gender, Culture, and Health, $3(1), 1-27$.

Sequeira, D., 2009. The Machismo and marianismo tango. Pittsburgh, PA: Dorrance Publ. Co., Inc.

Sinnott, J.D., J.S. Rabin, 2012. Sex roles. Encyclopedia of Human Behavior, 411-417 pp.

Shibley, J., J. DeLamater, 2006. Sexualidad humana (9 $9^{a}$ Ed.). México D.F., México: McGraw-Hill Publ. Comp. 
Succoff, C., 2001. Sociocultural contexts of time to first sex among hispanic adolescents. Journal of Marriage and Family, 4(63), 1158-1169.

Stoyanova, M., D.A. Hope, 2012. Gender, gender roles, and anxiety: Perceived confirmability of selfreport, behavioral avoidance, and physiological reactivity. Journal of Anxiety Disorders, 26(1), 206-214.

Tangmunkongvorakul, A., R. Kane, 2005. Gender double standar in young people attending sexual health services in Northern Thailand. Culture, Health \& Sexuality, 7(4), 361-373.

Thianthai, C., 2004. Gender and class differences in young people's sexuality and HVI/AIDS risktaking behaviours in Thailand. Culture, Health \& Sexuality, 6(3), 189-203.

Villarruel, A.M., D. Rodriguez, 2003. Beyond stereotypes: Promoting safer sex behaviors among Latino adolescents. Journal of Obstetric, Gynecologic \& Neonatal Nursing, 32(2), 258-263.

Viveros, M., 2002. La masculinidad como objeto de investigación y preocupación social. In: Vivieros, M. De quebradores y cumplidores: Sobre los hombres, masculinidades y relaciones de género en Colombia. Bogotá, Colombia: Universidad Nacional de Colombia, pp. 33-118.

Wolf, D.F., 1980. La mujer mexicana: La realidad y reflejo. Undergraduate thesis, Honors College, Ball State University, Muncie, ID, USA, 53 pp. 